\title{
Article \\ Problem Transformation as a Gateway to the Wider Use of Basic Computational Algorithms
}

\author{
Dalibor Gonda ${ }^{1}$, Gabriela Pavlovičová ${ }^{2}$, Viliam Ďuriš ${ }^{2, *(1)}$ and Anna Tirpáková ${ }^{2,3}$ (1) \\ 1 Department of Mathematical Methods and Operations Research, Faculty of Management Science and \\ Informatics, University of Žilina, Univerzitná 1, 01001 Žilina, Slovakia; daliborgonda@gmail.com \\ 2 Department of Mathematics, Faculty of Natural Sciences, Constantine The Philosopher University in Nitra, \\ Tr. A. Hlinku 1, 94901 Nitra, Slovakia; gpavlovicova@ukf.sk (G.P.); atirpakova@gmail.com (A.T.) \\ 3 Department of School Education, Faculty of Humanities, Tomas Bata University in Zlín, Štefánikova 5670, \\ 76000 Zlín, Czech Republic \\ * Correspondence: vduris@ukf.sk; Tel.: +421-37-6408-708
}

Citation: Gonda, D.; Pavlovičová, G.; Ďuriš, V.; Tirpáková, A. Problem Transformation as a Gateway to the Wider Use of Basic Computational Algorithms. Mathematics 2022, 10, 793. https://doi.org/10.3390/ math10050793

Academic Editor: Ángel Alberto Magreñán

Received: 1 February 2022 Accepted: 26 February 2022 Published: 2 March 2022

Publisher's Note: MDPI stays neutral with regard to jurisdictional claims in published maps and institutional affiliations.

Copyright: (c) 2022 by the authors. Licensee MDPI, Basel, Switzerland. This article is an open access article distributed under the terms and conditions of the Creative Commons Attribution (CC BY) license (https:/ / creativecommons.org/licenses/by/ $4.0 /)$.

\begin{abstract}
The problem transformation method is based on the idea that if we cannot solve the given problem directly, we will transfer it to a situation in which we know how to solve it. The basic feature of the method is the division of the problem into subtasks. Furthermore, it is the division of the problem solution into the solution of partial tasks that will allow the use of already learned algorithms outside the set of problems in which they were taught. The use of the method of transformation develops the necessary students' transformation skills, and, at the same time, it enables the greater use of ICT in mathematics teaching.
\end{abstract}

Keywords: algorithm; problem transformation; transformation skills; teaching mathematics

MSC: 68W01

\section{Introduction}

Mathematics plays a major role in developing human ideas, bringing about strategic and systematic reasoning processes used in problem analysis and problem solving. The National Council of Mathematics Teachers [1] stated that problem solving skills are the main benefit of teaching mathematics. In the school environment, a problem can be defined as any pedagogical situation that is created to ensure that students achieve a certain teaching goal [2]. Cruikshank and Sheffield [3] claim that the mathematical problem is a question or a situation related to mathematics, but not just related to numbers. To solve the problem, it is necessary to find the right method for the situation, using knowledge and experience. The assigned problem should stimulate and guide the student's activity to acquire competencies related to the proper implementation of activities related to a particular topic [4]. Additionally, the student should develop his/her skills to solve unknown problems as well. Navarro-Ibarra et al. [5] state that the teaching of mathematics is often based on passing on finished knowledge and its memorization. This is probably because many teachers consider passing on computational procedures to students as the main goal of teaching mathematics [6,7]. Mathematical problems are mainly used to practice learned techniques. In such targeted problems, students rely on memorized procedures and rules, which they often learn without understanding [8]. With this teaching system, students are accustomed to assigning a problem to a certain learned procedure or algorithm, and are taught (and are often able) to only solve problems on a specific transfer. According to Fuson et al. [9], problems requiring a specific transfer serve to apply knowledge and skills according to the presented model or in similar conditions. These are typical school problems that form a large part of the problems in teaching mathematics [10]. If students encounter a "non-standard" problem or a problem requiring a non-specific transfer (problem tasks), they expect the teacher to teach them a "new" solution algorithm. This creates 
a mentality for teaching mathematics, where students are "programmed" to solve a set of problems [11]. The pupil's role as a passive consumer of ready-made recipes to solve a limited set of problems means that the joy and enthusiasm of children in mathematics can be replaced by fear and disgust in school mathematics, in the form of methods, lessons, and algorithms that must be memorized [12]. Interestingly, Professor Hejný pointed out the undesirable effects of such a way of teaching mathematics in as early as 1990, warning of the formality of students' mathematical knowledge and skills. This formality is caused by the incorrect methodology of teaching mathematics, aimed at passing algorithms without insight [11]. However, Hejný [13] emphasizes that we need algorithms (recipes), otherwise the time needed to solve problems would be unnecessarily extended. The formalism of mastering algorithms can also be eliminated by the student gaining the necessary experience with algorithm creation. The aim of this article is to present a method of problem transformation that helps students to develop transformation skills and creatively use learned computational algorithms in problem solving.

\section{Algorithms and Their Teaching}

By algorithm, we mean a well-defined sequence of rules that tells us how to create certain output information, in a finite number of steps, from certain input information [14]. Papert [15] identified computational thinking with algorithmic thinking, in conjunction with the ability to apply mathematical concepts, in creating new, more reliable solutions to problems of a given type. The other authors refer to the algorithm as only some computational procedures, those that guarantee that the problem is solved if the steps of the procedure are performed in the specified order and without error $[16,17]$. The algorithm can also be characterized by its basic properties [18], which are as follows:

1. Elementality: a finite number of simple, easy-to-implement activities (the steps of the algorithm).

2. Determinability: after performing each step, we can tell if the algorithm is over, and if not, which step to follow.

3. Finality: the process described by the algorithm ends after a final time.

4. Resultivity: the algorithm keeps the calculation "safe" from the given input data to the result.

5. Bulk: the algorithm is designed to solve a large group of problems of the same type.

The place of the algorithms and the way they are taught has been the subject of many experts' discussions. They have even become the focal point of the so-called "mathematical warfare" [19], which sought to answer the question of how students can best acquire mathematical knowledge and skills. Many experts' studies, especially in the late 20th and early 21st centuries, speak negatively of the teaching of algorithms in mathematics lessons. For example, in the analysis of mathematics lessons using TIMSS 1999 [20], some mathematics lessons were described as "very algorithmic", "rule-oriented", and too focused on procedures and rules, without sufficient attention to understanding mathematical concepts and with little room for students' own thinking. Kamii and Dominick [21] concluded that algorithms are harmful in the development of children's numerical reasoning for the following two reasons: (a) they do not "teach" children to perceive diversity; (b) they force children to give up their own thinking. The negative perception of algorithms was also reflected in the fact that the teaching of algorithms was limited, or simply excluded, from the mathematics curricula and teaching in different countries (see, for example, [22]). In some countries, such as Manitoba [23], mathematics curriculum developers have avoided the term "algorithm". Gradually, however, the negative attitude towards algorithms began to be abandoned in professional circles, and a suitable place and way of teaching them began to be sought. For example, Clarke [24] states that formal (arithmetic) algorithms should not be implemented until children understand the meaning of numbers and their location. However, he acknowledged that formal algorithms are powerful procedures, especially when working with large numbers, which allow fast calculations. They provide a written record of the calculation, which also allows errors to be tracked and corrected. 
Teaching algorithms contributes to the recognition that it is possible to develop procedures that solve entire classes of problems, not just individual problems. By studying algorithms as "general procedures", students can learn that mathematics is well structured, highly organized, and full of patterns [25]. Algorithms have certain properties that suggest that they may be objects of learning at different cognitive levels [26]. The work of Fan and Bokhove [26] defined the following three cognitive levels of learning algorithms:

\section{(a) Cognitive level 1 [knowledge and skills]}

Students focus on memorizing the algorithm as a whole, without understanding the individual steps of the algorithm. The key activity of the students at this level is to remember the algorithm, so that they can reproduce it in simple situations, in which they have learned the algorithm. In the sense of Skemp's theory [27], this level can be identified with an "instrumental understanding", although Skemp's theory is about learning mathematics in general, and not directly about learning algorithms.

\section{(b) Cognitive level 2 [understanding]}

At this level, the product of learning is why the algorithm works and how it can be used in relatively complex situations. Understanding this allows for more flexible use of the acquired algorithm, thus expanding the set of problems that can be reliably solved by a given algorithm. This cognitive level corresponds to Skemp's "relationship understanding".

\section{(c) Cognitive level 3 [evaluation and design]}

At this level, there is a broader view of algorithms, rather than a set of tools for efficient problem solving. Algorithms are compared with each other, and own algorithms are generated. The student compares the individual algorithms, in order to select the most suitable algorithm for solving a given problem, or modifies the learned algorithm to the needs of solving the problem. It can be said that the learned algorithms harmonize with their own mathematical thinking.

In connection with this hierarchy, it should be emphasized that the "lower" cognitive level supports the "higher" cognitive level, and vice versa [26]. Although the cognitive levels described are largely hierarchical, the learning of algorithms may take place at different levels in different cases at the same time, and not necessarily sequentially from a lower cognitive level to a higher level.

\section{Ars Magna-Great Art}

In the 16th century, Ars Magna-The Great Art was called the ability to solve equations of the third and higher degree. The final note of Luca Pacioli's mathematical textbook from 1494 states that algebra does not know the solution of cubic equations. Until now, it has not been possible to find an algorithm for solving third-degree and higher equations, similar to solving linear or quadratic equations. There was a group of mathematicians who chose another way to find a new algorithm. Instead of looking for a new algorithm, they tried to solve the problem, so that they could use the knowledge already gained and, thus, the algorithms. In an effort to solve the cubic equation, they tried to rely on the knowledge from solving quadratic equations. The mathematicians at the time realized that the equation $a x^{2}+b x+c=0$, where $a, b, c \in \mathbb{Z}$, has either rational roots, or has roots in the form $x=u \pm \sqrt{v}$, where $u, v \in \mathbb{Q}$. They used this to transform a cubic equation into a quadratic equation, an equation whose computational algorithm they already knew. The idea of replacing one unknown with two other unknowns is the basis of the Vieto method of solving quadratic equations, which is illustrated by the following example:

Example 1. On the set $R$, solve the equation $4 x^{2}-8 x+1=0$.

Solution: The coefficients of the given equation are integers. We look for its roots in the form $x=u \pm v$, where $u, v \in R$. After substituting into the original equation, we solve the equation in the following form: 


$$
4(u+v)^{2}-8(u+v)+1=0 .
$$

After further modifications, we obtain the equation in the following form:

$$
4 u^{2}+(8 v-8) u+4 v^{2}-8 v+1=0 .
$$

By the above substitution, we transformed a quadratic equation with one unknown into a quadratic equation with two unknowns. We can solve this, thanks to the knowledge that if we have one equation and two unknowns, then we can replace one unknown with a specific value. In our case, it is reasonable to choose the unknown, so that $(8 v-8)=0$. Therefore, $v=1$. Substituting an unknown with this value, we obtain the following equation:

$$
4 u^{2}-3=0,
$$

where the solution is $u= \pm \frac{\sqrt{3}}{2}$. The roots of the given equation are $x_{1,2}=1 \pm \frac{\sqrt{3}}{2}$.

The idea of replacing one unknown with a pair of other unknowns, and the subsequent decomposition of one equation into a system, made it possible to solve cubic equations of the following type: $x^{3}+a x=b$. We provide an example (Example 2).

Example 2. Solve the equation $x^{3}+6 x=2$ on the set $\mathbb{R}$.

Solution: We find the solution of the given equation in the form $x=u+v$. After substituting for the original unknown and several modifications, we obtain an equation in the following form:

$$
u^{3}+v^{3}+3 u v x+6 x=2,
$$

which we then break down into a system of equations, as follows:

$$
u^{3}+v^{3}=2 \wedge 3 u v x+6 x=0 .
$$

The second equation shows that $u v=-2$, and, thus, $u^{3} v^{3}=-8$, which implies that $v^{3}=\frac{-8}{u^{3}} u^{3}$. After substituting into the first equation of the system, we have an equation with one unknown in the following form:

$$
u^{6}-2 u^{3}-8=0 \text {. }
$$

Its real roots, which we obtain by transforming it into a quadratic equation, by substituting $u^{3}=a$, are $4 \mathrm{a}-2$. By gradually substituting for the individual "auxiliary variables", we find that $x=\sqrt[3]{4}-\sqrt[3]{2}$ is the real root of the given equation.

Note: When we think more deeply about how to solve a given type of cubic equation, we can say that mathematicians have discovered a way to transform these cubic equations into solving a set of equations and quadratic equations. Thus, they found a way to turn an unknown problem into a problem they could solve. They created a method that uses transformations (most often using appropriate substitution) to "adjust" the problem, so that it can be used to solve already computational algorithms. It turns out that the idea of transforming an unknown problem into a known problem is a common way of thinking when looking for solutions to new mathematical problems. We describe the transformation method for solving a mathematical problem.

\section{Problem Transformation Method}

Although school algebra includes transformational aspects, focusing too much on adhering to rules when manipulating symbols will result in a lack of conceptual understanding of transformational activities [28,29]. Focusing on learning and using rules encourages students to learn algebra, as well as arithmetic. They expect that it is enough for them to learn formal procedures, where one step of the calculation predicts the next step [11], which is not sufficient for the development of transformation skills. Thus, learning algebra 
after arithmetic requires the student to build a different way of thinking [30]. Algebra and arithmetic are useful for solving problems, but the approach to solving them is different. Unlike arithmetic, the main purpose of algebra is not to perform numerical calculations, but to provide an operating language for the representation, analysis, and manipulation of relationships contained in numbers and letters. According to Kieran [31], algebra includes generational, transformational, and meta-global levels. These three skills are crucial for algebraic thinking, and should, therefore, be the most important part of teaching algebra [32]. Substituting numerical values into algebraic expressions can be considered a basic transformation skill. This skill is very important because it is related to proving the equivalence of two algebraic expressions. Algebraic expressions are equivalent if, and only if, any substitution of numerical values into expressions leads to the same results. Another key transformation skill concerns the manipulation of symbolic expressions [33], and it is closely linked to the essence of mathematical equivalence. Mathematical equivalence must also already be perceived as the equivalence of two mathematical symbolic notations. The transformation activities in the manipulation of expressions are aimed at either simplifying the expression (also within the solution of the equation) or at identifying a subexpression that will be replaced by another expression. These activities are interconnected, and both are based on the acquisition of equivalence, but the other of them causes problems for students. Students can adjust the following equation:

$$
4 \log _{3}(2 x+1)+\log _{3} \sqrt{2 x+1}=\frac{3}{2} \log _{3}^{2}(2 x+1)-6
$$

using logarithmic rules to the shape $\frac{9}{2} \log _{3}(2 x+1)=\frac{3}{2} \log _{3}^{2}(2 x+1)-6$.

However, many students do not view this equation as quadratic because the subexpression $\log _{3}(2 x+1)$ is not considered an object [34] that can be "renamed" with another symbol and, thus, transform the problem. The perception of algebraic expressions as objects that can be replaced by another variable, without disturbing the content of the object, is fundamental to the ability to transform the problem. The transformation of a problem is a thought process that does not solve the problem, but changes it to another [13]. For example, the problem of solving a logarithmic equation is transformed into a problem of solving a quadratic equation. The method of problem transformation is, therefore, based on the idea that if we cannot solve the given problem directly, then we will transfer it to a situation in which we know how to solve it. We will solve the transformed problem and return the result to the original situation. The use of the problem transformation method leads to the division of the problem solution into several subproblems. If we solve these subproblems, we will also solve the given problem. Additionally, it is the division of the problem solution into the solution of partial problems that will allow the use of already learned algorithms outside the set of problems in which they were taught. The essence of the problem transformation method can be illustrated to students who already know how to solve algebraic equations.

Example 3. Solve the equation on the set $\mathbb{R}: 2 \sqrt{x}+\sqrt[8]{x^{5}}=3 \sqrt[4]{x^{3}}$.

Solution: The given example represents a problem for students because they have not yet encountered a solution of this type of equation. However, the new type of equation may not automatically lead to the need to learn a new calculation algorithm. With a given non-algebraic equation, it is useful to consider whether it is possible to transform it into an algebraic equation. We have just formulated a subproblem that we will solve. Since algebraic equations do not contain square roots, we will try to achieve this goal by "sensibly renaming" some subexpressions. To accomplish this, it is necessary to manipulate the expressions using already known equivalences, such as the following:

$$
\sqrt[m]{a^{n}}=a^{\frac{n}{m}}=(\sqrt[m]{a})^{n}
$$


Individual roots can be written as powers, with a rational exponent $2 x^{\frac{1}{2}}+x^{\frac{5}{8}}=3 x^{\frac{3}{4}}$. Subsequently, we adjust the individual exponents to fractions with the same denominator, $2 x^{\frac{4}{8}}+x^{\frac{5}{8}}=3 x^{\frac{6}{8}}$, and, finally, we write the individual powers in the form of square roots, $2(\sqrt[8]{x})^{4}+(\sqrt[8]{x})^{5}=3(\sqrt[8]{x})^{6}$.

With these targeted (strategic) adjustments, we have created a repetitive expression in the equation that allows for "reasonable renaming" (introduction of substitution) in the form $\sqrt[8]{x}=y$. The found substitution means that the given equation can be transformed into an algebraic equation. This solves the first subproblem. After introducing the substitution $\sqrt[8]{x}=y$, we solve the transformed problem and, thus, the equation of the sixth degree, as follows:

$$
2 y^{4}+y^{5}-3 y^{6}=0 .
$$

Another subproblem is to find the answer to the question of whether Equation (1) can be transformed into an equation of, at most, the second degree, because we know the algorithm for solving such equations. Further manipulation of the expressions gives the following equation:

$$
y^{4}\left(2+y-3 y^{2}\right)=0 .
$$

Equation (2) is in product form. For the equality (LS) $=(\mathrm{RS})$ to apply, it is sufficient that at least one of the members of the product on the left is equal to zero. Therefore, the problem is transformed again to solve two separate equations, as follows:

$$
y^{4}=0 \quad \vee \quad\left(2+y-3 y^{2}\right)=0 .
$$

We can solve this problem using learned algorithms. The solution to the first of the equations is $y_{1}=0$, and the other is $y_{2}=1 ; y_{3}=-\frac{2}{3}$.

The obtained results now need to be transferred to the original situation. Thus, it is necessary to calculate the values of the original unknown $x$. To achieve this, we use the equivalence $\sqrt[8]{x}=y$, defined by us, and the numerical values that can be substituted for the variable $y$. Therefore, we solve three equations, as follows:

$$
\sqrt[8]{x}=0 \quad \vee \quad \sqrt[8]{x}=1 \quad \vee \quad \sqrt[8]{x}=-\frac{2}{3} .
$$

The solution of the first is $x_{1}=0$, the second is $x_{2}=1$, and the third has no solution on the set $\mathbb{R}$. The set of solutions of the given equation is $K=\{0,1\}$.

Based on the above, the transformation method can be divided into individual steps, which are shown in Figure 1.

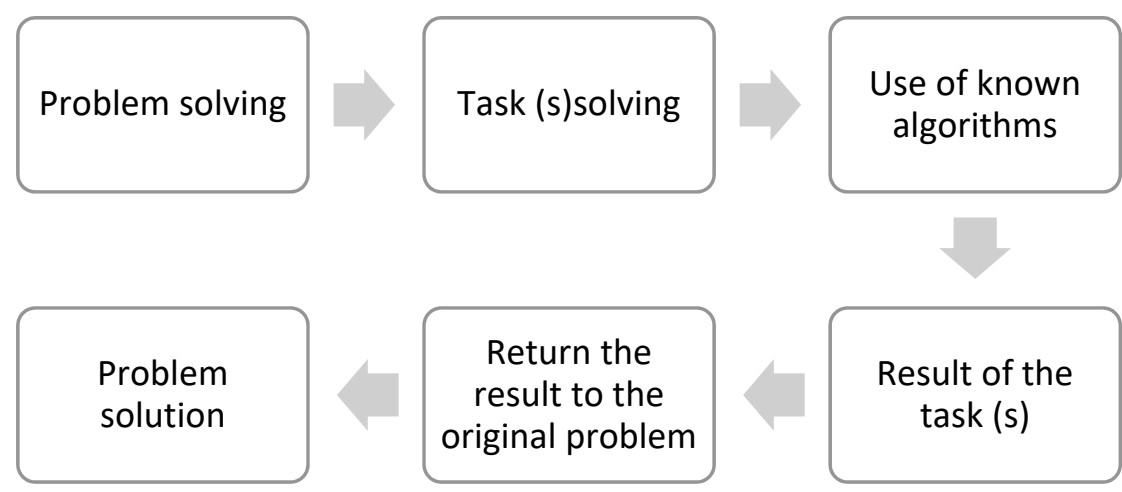

Figure 1. Phases of the problem transformation method.

\section{Discussion}

Conrad Wolfram (director of one of the most important mathematical societies in the world—Wolfram Research, Inc., Champaign, IL, USA) strongly criticizes the prevailing 
approach to teaching mathematics based on manual calculations. Numerical calculations can be performed by computers, thanks to suitable software (e.g., MATHEMATICA/DERIVE/MATLAB), which also guarantees a correct numerical result. According to Boaler [10], a correct or incorrect result cannot be considered an unambiguous confirmation of the quality of the students' mathematical abilities. A PISA test measures the level of mathematical literacy of students in individual countries. Mathematical literacy is the ability of a person to express, use, and interpret mathematics in various contexts [35]. The World Economic Forum, in its 2016 declaration, stated that it expects graduates in 2020 to be able to deal, independently, with issues they have not encountered before, and to also be able to consider a variety of information and combine it into one solution. To achieve this, they need the ability to obtain an overall view of the problem being solved in a given context. The ability to observe the details, which are often crucial in finding the right solution to a problem, is also important. Fisk [36] explains that the new vision of learning supports students not only in acquiring the necessary skills and knowledge, but also in their ability to identify a resource through which these skills and knowledge can be learned and further improved, and this resource should be largely educated at individual school levels. We think that teaching mathematics at high schools and universities, based on the problem transformation method (MTP), is a proper tool for developing the above-mentioned expected competencies. The ability to transform a problem, or part of it, is fundamental to success in higher mathematics and problem solving in general [37].

The solution to the problem, by means of MTP, corresponds to the scheme established in 1910 by J. Dewey [38] (Figure 2).

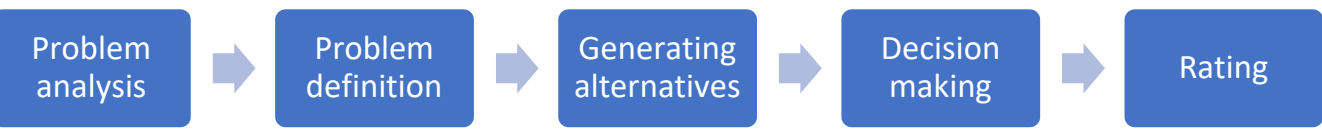

Figure 2. Basic stages of problem solving.

Students need to be aware of the need to spend time analyzing the problem. The analysis of the assignment and the subsequent definition of the problem leads to the identification of mathematics that is "hidden" in the assigned problem. This process allows the natural use of mathematics and mathematical thinking [39], which consists of mathematizing the problem - creating a mathematical model of the problem. The mere creation of a mathematical model is a transformation of the problem that will allow the application of mathematical methods. The created mathematical model can represent a problem for the student, the solution of which he/she knows and will solve by using a suitable algorithm. However, the created model can also be a problem that the student does not know how to solve. However, the transformation skills acquired in teaching MTP may offer an opportunity to continue solving a problem by transforming it into another mathematical problem. Due to the frequent use of MTP in the teaching of mathematics, it is not limited to only solving a problem in the problem area in which it is assigned.

The ability to divide a problem is needed to effectively use the transformation skills. The division of the problem has an important place in the phase of generating alternatives and in the evaluation of their impact on solving the problem. According to Phonapichat et al. [40], students are not interested in solving long and complex problems. However, division leads to the need to solve simple problems. The ability to divide a problem also changes students' attitudes towards algorithms. They no longer perceive them as just things to be learned, if they need to solve problems, but they realize that the process of solving a problem is a combination of several short algorithms. Students are able to "insert" these short algorithms into their problem, due to their ability to divide the problem. Together with the ability to divide the problem, a creative tension in solving the problem occurs. According to [13], students who are able to divide the process of solving a problem perceive its solution as their own creative work, and they also build a mathematical ability to solve other problems they have not yet encountered in mathematics teaching [41]. 
As mastering MTP allows students to apply already learned algorithms when solving problems, teaching mathematics using this method can be linked to ICT in education. According to Wolfram [42], the calculations are already performed by computers today. The solver is expected to be able to divide and transform the problem so that the available software can be used for individual calculations. The skills developed by using MTP bring a division of work in which part is solved by the student and part by the computer. According to Carmen Ramírez-Rueda et al. [43], the involvement of ICT in teaching should play a supporting role.

We think that the purposeful application of MTP to the teaching of mathematics extends the procedural acquisition of algorithms by their conceptual understanding. However, transformation skills also require a conceptual understanding of mathematical concepts and their interrelationship. Thus, procedural and conceptual knowledge is integrated within MTP, which increases the success of students in solving problems [44-46].

Another benefit of teaching MTP is the knowledge that transforming a problem will allow the problem to be changed to simpler problems, without the need to learn new computational techniques. Students will gradually gain the knowledge that new minor problems do not require learning new techniques, but it is enough to creatively use the knowledge already acquired.

\section{Conclusions}

Students usually consider mathematics to be a subject where they are expected to perform and find results quickly [10]. Even according to the research by Ayalon and Even [47], there is widespread fear and resistance to mathematics. According to [17], students prefer learning algorithms because they give them a sense of security. They think that by remembering an algorithm and assigning it to a given problem, they will be successful in mathematics. Over time, the number of computational procedures grows, and, with it, the belief that mathematics is a subject of calculations, procedures, and rules [48]. We think that developing students' transformation skills and mastering the method of transforming the problem can reverse this negative trend. This is because the ability to transform a problem will allow the use of learned algorithms outside the set of problems, where students have mastered them and connected them to each other in solving new problems. It also leads to a reduction in the number of memorized procedures. The method of transforming the problem, and the transformation skills developed in addition, will enable students to gradually perceive mathematics as a creative subject that develops their thinking. Research has been conducted to illustrate that the purposeful incorporation of transformational activities into the teaching of mathematics has a positive effect on the development of students' algebraic thinking [49]. Other research results show that if we want to develop students' algebraic thinking, it is necessary to include more transformational activities in the teaching of mathematics [33].

Author Contributions: Data curation, G.P.; Formal analysis, V.Ď.; Investigation, D.G.; Methodology, D.G.; Project administration, A.T.; Resources, G.P.; Supervision, A.T.; Validation, V.Ď. All authors have read and agreed to the published version of the manuscript.

Funding: This research received no external funding.

Institutional Review Board Statement: Not applicable.

Informed Consent Statement: Not applicable.

Data Availability Statement: Not applicable.

Conflicts of Interest: The authors declare no conflict of interest. 


\section{References}

1. National Council of Teachers of Mathematics (NCTM). Problem Solving. Standards and Focal Points. 2012. Available online: http:/ / www.nctm.org/standards/content.aspx?id=26860 (accessed on 21 December 2021).

2. Mašbic, E.I. Psichologičeskij Analiz Učebnoj Zadači. Sovetskaja Pedagogika. 1973. Available online: http:/ / pages.pedf.cuni.cz/ pedagogika / ?attachment_id=5308\&edmc $=5308$ (accessed on 31 January 2022).

3. Crulikshank, D.E.; Sheffeild, L.J. Teaching and Learning Elementary School; Macmillan Publishing Company: New York, NY, USA, 1992.

4. Mínguez-Aroca, F.; Moll-López, S.; Llobregat-Gómez, N.; Sánchez-Ruiz, L.M. A Cuboid Registers Topic, Activity and Competency Data to Exude Feedforward and Continuous Assessment of Competencies. Mathematics 2022, 10, 415. [CrossRef]

5. Navarro-Ibarra, L.; García-Santillán, A.; Cuevas-Salazar, O.; Ansaldo-Leyva, J. Mathematics, Technology and Learning: How to Align These Variables in Order to Explain Anxiety Towards Mathematics and Attitude Towards the Use of Technology for Learning Mathematics. EURASIA J. Math. Sci. Technol. Educ. 2017, 13, 6211-6229.

6. Lukhele, R.B.; Murray, H.; Olivier, A. Learners' understanding of the addition of fractions. In Proceedings of the Fifth Annual Congress of the Association for Mathematics Education of South Africa, Port Elizabeth, South Africa, 5-9 July 1999; Port Elizabeth Technikon: Port Elizabeth, South Africa, 1999; Volume 1, pp. 87-97.

7. Leung, F.K.S. Mathematics education in East Asia and the West: Does culture matter? In Mathematics Education in Different Cultural Traditions: A Comparative Study of East Asia and the West; Leung, F.K.S., Graf, K.-D., Lopez-Real, F.J., Eds.; Springer: New York, NY, USA, 2006; pp. 21-46.

8. Fuson, K.C.; Kalchman, M.; Bransford, J.D. Mathematical understanding: An introduction. How Students Learn: History, Mathematics, and Science in the Classroom; The National Academies Press: Washington, DC, USA, 2005; pp. 217-256.

9. Niemierko, B. Taksonomia celów wychowania. Kwart. Pedag. 1979, 24, 66-67.

10. Boaler, J. Mathematical Mindsets; Jossey-Bass: Hoboken, NJ, USA, 2015.

11. Freudenthal, H. Didactical Phenomenology of Mathematical Structures; Springer Science \& Business Media: Berlin, Germany, 1986; Volume 1.

12. Escalera Chávez, M.E.; Moreno García, E.; Rojas Kramer, C.A. Confirmatory Model to Measure Attitude towards Mathematics in Higher Education Students: Study Case in SLP Mexico. Int. Electron. J. Math. Educ. 2019, 14, 163-168.

13. Hejný, M. Teória Vyučovania Matematiky 2; SPN: Bratislava, Slovakia, 1990.

14. Knuth, D.E. Computer science and its relation to mathematics. Am. Math. Mon. 1974, 81, 323-343. [CrossRef]

15. Papert, S. An exploration in the space of mathematics educations. Int. J. Comput. Math. Learn. 1996, 1, 95-123. [CrossRef]

16. Anderson, J.R. Acquisition of cognitive skill. Psychol. Rev. 1982, 89, 369-406. [CrossRef]

17. Star, J.R. Reconceptualizing procedural knowledge. J. Res. Math. Educ. 2005, 36, 404-411.

18. Znám, Š.; Bukovský, L.; Hejný, M.; Hvorecký, J.; Riečan, B. Pohl'ad do Dejín Matematiky; Alfa: Bratislava, Slovakia, 1986.

19. Schoenfeld, A.H. Problem solving in the United States, 1970-2008: Research and theory, practice and politics. ZDM-Int. J. Math. Educ. 2007, 39, 537-551. [CrossRef]

20. Givvin, K.B.; Jacobs, J.; Hollingsworth, H.; Hiebert, J. What is effective mathematics teaching? International educators' judgments of mathematics lessons from the TIMSS 1999 Video Study. In Effective Mathematics Teaching from Teachers' Perspectives: National and Cross-National Studies; Cai, J., Kaiser, G., Perry, B., Wong, N.-Y., Eds.; Sense: Boston, MA, USA, 2009; pp. 37-39.

21. Kamii, C.; Dominick, A. To teach or not to teach algorithms. J. Math. Behav. 1997, 16, 51-61. [CrossRef]

22. Budd, K.; Carson, E.; Garelick, B.; Klein, D.; Milgram, R.J.; Raimi, R.A.; Schwartz, M.; Stotsky, S.; Williams, V.; Wilson, W.S. Ten Myths about Math Education and Why We Shouldn't Believe Them. 2005. Available online: http://www.nychold.com/myths-05 0504.html (accessed on 29 April 2014).

23. Manitoba Education, Citizenship and Youth. Manitoba Curriculum Framework of Outcomes: Kindergarten to Grade 8 Mathematics, Manitoba: Winnipeg, MB, Canada, 2008.

24. Clarke, D. Written algorithms in the primary years: Undoing the "good work". In Making Mathematics Vital: Proceedings of the Twentieth Biennial Conference of the Australian Association of Mathematics Teachers; Coupland, M., Anderson, J., Spencer, T., Eds.; Australian Association of Mathematics Teachers: Adelaide, Australia, 2005; pp. 93-98.

25. Kilpatrick, J.; Swafford, J.; Findell, B. Adding It up: Helping Children Learn Mathematics; National Research Council, Ed.; National Academy Press: Washington, DC, USA, 2001; p. 2101.

26. Fan, L.; Bokhove, C. Rethinking the role of algorithms in school mathematics: A conceptual model with focus on cognitive development. ZDM 2014, 46, 481-492. [CrossRef]

27. Skemp, R.R. Relational understanding and instrumental understanding. Math. Teach. 1976, 77, 20-26.

28. Kieran, C. Learning and teaching algebra at the middle school through college levels. In Second Handbook of Research on Mathematics Teaching and Learning: A Project of the National Council of Teachers of Mathematics; Lester, F.K., Ed.; Information Age Publishing: Charlotte, NC, USA, 2007; pp. 707-762.

29. Usiskin, Z. Conceptions of school algebra and uses of variables. In The Ideas of Algebra, K-12; Coxford, A.F., Ed.; National Council of Teachers of Mathematics: Reston, VA, USA, 1988; pp. 8-19.

30. Agoestanto, A.; Sukestiyarno, Y.L. An analysis on generational, transformational, global meta-level algebraic thinking ability in junior high school students. J. Phys. Conf. Ser. 2019, 1321, 032082. [CrossRef]

31. Kieran, C. Algebraic thinking in the early grades: What is it. Math. Educ. 2004, 8, 139-151. 
32. Lozano, M.D. Using enactivism as a methodology to characterise algebraic learning. ZDM 2015, 47, 223-234. [CrossRef]

33. Pedersen, I.F. What characterizes the algebraic competence of Norwegian upper secondary school students? Evidence from timss advanced. Int. J. Sci. Math. Educ. 2015, 13, 71-96. [CrossRef]

34. Jupri, A.; Drijvers, P.H.M.; den Heuvel-Panhuizen, V. An instrumentation theory view on students' use of an applet for algebraic substitution. Int. J. Technol. Math. Educ. 2016, 23, 63-80.

35. Niss, M. Mathematical competencies and PISA. Assessing Mathematical Literacy; Springer: Cham, Switzerland; New York, NY, USA, 2015; pp. 35-55, ISBN 9783319101217.

36. Fisk, W.J. The ventilation problem in schools: Literature review. Indoor Air 2017, 27, 1039-1051. [CrossRef]

37. Feikes, D.; Schwingendorf, K. The Importance of Compression in Children's Learning of Math. and Teacher's Learning to Teach Mathematics. Mediterr. J. Res. Math. Educ. 2008, 7, 59-69.

38. Dewey, J. How We Think; D. C Heath \& Co. Publishers: Chicago, IL, USA; Boston, MA, USA, 1910.

39. Devlin, K. The Math Instinct: Why Your're a Mathematical Genius (Along with Lobsters, Birds, Cats, and Dogs); Basic Book: New York, NY, USA, 2006; p. 288. ISBN 9781560258391.

40. Phonapichat, P.; Wongwanich, S.; Sujiva, S. An analysis of elementary school students' difficulties in mathematical problem solving. Proc. Soc. Behav. Sci. 2014, 116, 3169-3174. [CrossRef]

41. Rahmi, S.; Nadia, R.; Hasibah, B.; Hidayat, W. The Relation between Self-Efficacy toward Math with the Math Communication Competence. Infinity 2017, 6, 177-182. [CrossRef]

42. Wolfram, C. Teaching Kids Real Math with Computers. 2010. Available online: http://www.ted.com/talks/conrad_wolfram_ teaching_kids_real_math_with_computers.html (accessed on 13 October 2015).

43. Carmen Ramírez-Rueda, M.; Cózar-Gutiérrez, R.; Colmenero, M.J.R.; González-Calero, J.A. Towards a coordinated vision of ICT in education: A comparative analysis of Preschool and Primary Education teachers' and parents' perceptions. Teach. Teach. Educ. 2021, 100, 103300. [CrossRef]

44. Baroody, A.J. The development of adaptive expertise and flexibility: The integration of conceptual and procedural knowledge. In The Development of Arithmetic Concepts and Skills: Constructing Adaptive Expertise; Baroody, A.J., Dowker, A., Eds.; Erlbaum: Mahwah, NJ, USA, 2003; Volume 516, pp. 1-34, ISBN 9780805831566.

45. Rittle-Johnson, B.; Star, J.R.; Durkin, K. Developing procedural flexibility: Are novices prepared to learn from comparing procedures? Br. J. Educ. Psychol. 2012, 82, 436-455. [CrossRef] [PubMed]

46. Rittle-Johnson, B.; Schneider, M. Developing conceptual and procedural knowledge of mathematics. In Oxford Handbook of Numerical Cognition; Oxford University Press: Oxford, UK, 2015; pp. 1118-1134. [CrossRef]

47. Ayalon, M.; Even, R. Students' opportunities to engage in transformational algebraic activity in different beginning algebra topics and classes. Int. J. Sci. Math. Educ. 2015, 13, 285-307. [CrossRef]

48. Silva, E.; White, T. Pathways to Improvement: Using Psychological Strategies to Help College Students Master Developmental Math; Carnegie Foundation for the Advancement of Teaching: Stanford, CA, USA, 2013.

49. Devlin, K. Mathematics: The Science of Patterns: The Search for Order in Life, Mind and the Universe; Scientific American Library: New York, NY, USA, 1997. 